\title{
PERCEPÇÕES DE MEIO AMBIENTE EM ESTUdANTES DE INSTITUIÇÕES DE ENSINO GEOGRÁFICA E CULTURALMENTE DISTINTAS
}

\author{
ENVIRONMENTAL PERCEPTIONS IN STUDENTS OF GEOGRAPHIC AND CULTURALLY \\ DIFFERENT EDUCATION INSTITUTIONS
}

PERCEPCIONES DEL MEDIO AMBIENTE EN ESTUDIANTES DE INSTITUCIONES DE EDUCACIÓN GEOGRÁFICAS Y CULTURALMENTE DIFERENTES

\section{Damon Ferreira Farias \\ iD (9) \\ Doutorado em Ciências e \\ Engenharia dos Materiais (UFS) \\ Professor no Colégio Estadual do \\ Campo de Campo Formoso \\ (CECCF) \\ damon.fisica@gmail.com}

\section{Flávia Noelia Pucheta (iD) 9}

Mestrado em Evolução Crustal e

Recursos Naturais

flavia.noelia@ifmg.edu.br

\section{Cláudio Alves Pereira

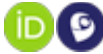

Mestrado profissional em

Educação (UFLA)

Professor no curso de Pós-

Graduação Lato Sensu em

Docência - IFMG Campus Arcos

claudio.pereira@ifmg.edu.br

\begin{abstract}
Resumo
$\mathrm{O}$ estudo buscou investigar as apropriações de significados de conceitos de Meio Ambiente por parte de estudantes do ensino médio separados geográfica e culturalmente, sendo um dos grupos vinculado a uma instituição estadual do tipo Escola do Campo localizada em Campo Formoso, estado da Bahia e o segundo composto por estudantes do curso Técnico em Meio Ambiente, na modalidade de ensino técnico integrado ao médio, de um Instituto Federal com campus em Governador Valadares, estado de Minas Gerais. O estudo é do tipo exploratóriodescritivo e utilizou formulário eletrônico para coletar as informações, devido ao distanciamento imposto pela pandemia da Covid-19. O resultado apontou a necessidade de se considerar a inclusão da Educação Ambiental de forma a permear todo o currículo do estudante do Ensino Médio, adotando-se o enfoque crítico e aplicada a questões do cotidiano desses sujeitos, potencializando aprendizados que se materializarão em transformação social e preservação ambiental.
\end{abstract}

Palavras-chave: Educação Ambiental. Educação Básica. Sociedade Sustentável.

Recebido em: 10 de abril de 2021. Aprovado em: 24 de maio de 2021.

Como citar esse artigo (ABNT):

FARIAS; Damon Ferreira; PUCHETA, Flávia Noelia; PEREIRA, Cláudio Alves. Percepções de meio ambiente em estudantes de instituições de ensino geográfica e culturalmente distintas. Revista Prática Docente, v. 6, n. 2, e034, 2021. http://doi.org/10.23926/RPD.2021.v6.n2.e034.id1137 


\section{Abstract}

The study sought to investigate the appropriations of meanings of Environment concepts by high school students separated geographically and culturally, being one of the groups linked to a state institution of the type Escola do Campo located in Campo Formoso, state of Bahia is the second one composed by students of the Technical course in Environment, in the modality of technical education integrated to high school, from a Federal Institute with a campus in Governador Valadares, state of Minas Gerais. The study is exploratory-descriptive and used an electronic form to collect information, due to the distance imposed by the Covid-19 pandemic. The result pointed to the need to consider the inclusion of Environmental Education in order to permeate the entire curriculum of the high school student, adopting a critical approach and applied to the daily issues of these subjects, enhancing learning that will materialize in social transformation and environmental preservation.

Keywords: Environmental Education. Basic Education. Sociedad Sustentive.

\section{Resumen}

El estudio buscó investigar las apropiaciones de significados de los conceptos de Medio Ambiente por parte de estudiantes de secundaria separados geográfica y culturalmente, siendo uno de los grupos vinculados a una institución estatal del tipo Escuela del Campo ubicada en Campo Formoso, provincia de Bahía y la segunda compuesta por estudiantes del curso Técnico en Medio Ambiente, en la modalidad de educación técnica integrada al bachillerato, de un Instituto Federal con campus en Governador Valadares, provincia de Minas Gerais. El estudio es exploratoriodescriptivo y utilizó un formulario electrónico para recolectar la información, debido a la distancia impuesta por la pandemia del Covid-19. El resultado apontó la necesidad de considerar la inclusión de la Educación Ambiental con el fin de impregnar todo el currículo del estudiante de Bachillerato, adoptando el enfoque crítico y aplicado a los asuntos cotidianos de estos sujetos, mejorar los aprendizajes que se materializarán en la transformación social y la preservación del medio ambiente.

Palabras clave: Educación Ambiental. Educación Básica. Sociedad Sustentable. 


\section{INTRODUÇÃ̃o}

Nas últimas décadas, muito tem se discutido e divulgado sobre a Educação Ambiental, preservação do meio ambiente e desenvolvimento sustentável, haja vista a quantidade de recomendações globais e políticas públicas nacionais que apresentam esse foco (ONU, 1972; BRASIL, 1998; 1999). Frente aos graves problemas ambientais que nos atingem em vários níveis (local, regional, nacional e global), torna-se cada vez mais necessário o desenvolvimento de práticas educativas voltadas a uma sensibilização para a preservação do meio ambiente, bem como zelar pela prática deste princípio em outros ambientes sociais para além da escola, abarcando processos que abordem a multiplicidade de fatores que essa temática traz consigo. Dessa forma, a Educação Ambiental (EA) passa a ser uma das estratégias significativas para a construção de uma nova mentalidade de desenvolvimento, lançando mão da utilização sustentável dos recursos naturais, priorizando o crescimento econômico com equidade social e o equilíbrio ecológico (GASQUES et al., 2016).

A EA alcançou maior destaque no cenário nacional na década de 1980, especialmente com a promulgação da Lei $n^{\circ}$ 6.938/1981 que instituiu a Política Nacional de Meio Ambiente (PNMA). Com a aprovação da Constituição Federal (1988) no final da década, o texto da Carta Magna reservou a todos os brasileiros em seu Art. 225 "o meio ambiente ecologicamente equilibrado, bem de uso comum do povo e essencial à sadia qualidade de vida, impondo-se ao poder público e à coletividade o dever de defendê-lo e preservá-lo para as presentes e futuras gerações" (BRASIL, 1988, p. 131).

A Lei no 9795/1999 instituiu a Política Nacional de Educação Ambiental (PNEA). A partir dessa lei, a EA é entendida como "o conjunto dos processos por meio dos quais o indivíduo e a coletividade constroem valores sociais, conhecimentos e competências voltadas para a conservação do meio ambiente e sua sustentabilidade" (BRASIL, 1999, p. 1).

O primeiro Censo Escolar que incluiu questões sobre a EA aconteceu em 2001. Nesse mesmo ano, foi possível observar que 61,2\% das escolas brasileiras declararam trabalhar com esta temática em suas dependências. Os dados trazidos pelo Censo Escolar de 2004 já indicavam que este percentual havia saltado para 94\%, conforme apontam Veiga, Amorim e Blanco (2005) e Trajber e Mendonça (2007).

Levando em conta os estudos que se dedicaram a investigar a EA escolar, podemos confirmar que, embora a temática EA tenha chegado às escolas brasileiras, as práticas educativas ainda têm se mostrado bastante fragilizadas e pouco críticas (FRIZZO; 
CARVALHO, 2018). Ainda conforme as autoras, verifica-se que a EA tem sido silenciada nas políticas educacionais mais recentes, como por exemplo nos textos do Programa Novo Mais Educação (BRASIL, 2016), no Plano Nacional de Educação 2014-2024 (BRASIL, 2014) e na Base Nacional Comum Curricular (BRASIL, 2018).

Dados históricos do Instituto Nacional de Estudos e Pesquisas Educacionais Anísio Teixeira (Inep) identificam que uma das grandes dificuldades para a inserção da EA nas práticas escolares está relacionada à precariedade de recursos materiais, além do necessário investimento em estudos para o aprofundamento de temas ambientais e educacionais, inclusive para a formação continuada dos professores. Assim, estariam aqui alguns dos principais desafios para verdadeiramente incluir a EA nos cotidianos das instituições de ensino em nosso país (TRAJBER; MENDONÇA, 2007; SANTOS, 2009; RAYMUNDO et al., 2019).

Muitas vezes não dispondo de material adequado ou tendo-o em quantidade suficiente para realizar seus trabalhos, os professores têm procurado fontes diversas para trabalhar a EA no ambiente escolar. Nem sempre com adequada qualidade acadêmica e científica, o trabalho tem avançado, apesar de não atingir todos os benefícios possíveis junto à comunidade escolar e à sociedade, no geral.

Nesse sentido, este estudo tem o objetivo de identificar se os estudantes do ensino médio das duas instituições de ensino selecionadas, distintas geográfica e culturalmente, reconhecem práticas pedagógicas que trabalham conceitos da EA no cotidiano dos seus cursos. Com isso, busca-se inserir nesse campo de pesquisa e contribuir com dados para identificar potencialidades da inclusão da discussão ambiental no ambiente escolar e as possibilidades de ganhos dessa prática para a formação cidadã dos estudantes.

\section{Procedimentos Metodológicos}

A pesquisa é do tipo exploratória e descritiva, assumindo uma abordagem qualitativa no tratamento dos dados coletados. Para Gil (2002) e Vieira (2002), a pesquisa exploratória tem por objetivo favorecer uma maior proximidade com o tema, tornando-o mais claro, além de propiciar ao pesquisador maior intimidade com o assunto, possibilitando a compreensão do problema. Ainda conforme os autores, caracteriza-se também como descritiva, pois os fatos serão observados, analisados, registrados, classificados e interpretados, sem que o pesquisador interfira nesses. 
A abordagem qualitativa deste estudo se mostra pertinente aos objetivos da pesquisa. Com a proposta de ser exploratório, a escolha de analisar os dados qualitativamente permitirá que observemos os detalhes das respostas dos dois grupos de estudantes sobre a EA.

O propósito deste estudo fez com que, desde o início, os estudantes fossem tratados em dois grupos distintos, partindo-se da hipótese de que as diferenças geográficas e culturais influenciariam no entendimento de cada grupo sobre a temática EA.

Para a coleta de dados, utilizou-se um formulário com treze questões desenvolvido na plataforma Google Forms. A opção pelo uso do meio eletrônico para a construção e divulgação do formulário teve como principal motivador o cenário de necessário distanciamento social trazido pela pandemia do Covid-19. Assim, o link para acesso ao formulário foi enviado por email aos estudantes das duas instituições de ensino.

$\mathrm{Na}$ correspondência eletrônica constava o convite formal para participar da pesquisa e a identificação do prazo para retorno do formulário (todo o mês de setembro 2020). Ao final, o formulário obteve um conjunto amostral de 25 respondentes, sendo 12 estudantes da escola Rural e 13 estudantes da escola Urbana. É importante destacar que o formulário foi liberado somente àqueles que manifestaram interesse em participar voluntariamente do estudo e que retornaram o Termo de Consentimento Livre e Esclarecido - TCLE (assinado pelo estudante maior de idade ou pelo seu responsável legal, se menor) e o Termo de Assentimento Livre e Esclarecido - TALE (para estudantes menores de idade).

O formulário foi organizado com perguntas objetivas e subjetivas e teve o intuito de analisar os seguintes pontos: (i) o perfil dos estudantes; (ii) mapeamento de práticas pedagógicas vinculadas à EA nas escolas; e (iii) identificar o entendimento dos estudantes sobre questões ambientais que podem refletir em seus cotidianos.

Participaram da pesquisa estudantes voluntários do $(i)$ segundo e terceiro anos do Ensino Médio (escola Rural), e do (ii) segundo, terceiro e quarto anos do curso Técnico em Meio Ambiente Integrado ao Ensino Médio (escola Urbana), regularmente matriculados no segundo semestre do ano 2020.

\section{RESUltados E DISCUSSÕES}

Este estudo abordou dois grupos de estudantes localizados em dois municípios bem distantes: um locus urbano (Ensino Técnico Integrado em Meio Ambiente no IFMG Campus Governador Valadares) e um locus rural (Colégio Estadual do Campo de Campo Formoso BA, Anexo Tuiutiba). Embora tenha a identificação de "Escola do Campo", é importante 
destacar que o colégio baiano não trabalha com a Pedagogia da Alternância. Assim, a organização curricular, a distribuição das séries e o calendário escolar são organizados conforme a maioria das escolas brasileiras: currículo estruturado em disciplinas específicas, calendário com aulas de março a dezembro, com recesso escolar em junho. De maneira a tornar a leitura mais fluida, trataremos as instituições de ensino como Urbana e Rural, respectivamente.

A escola Urbana atende, principalmente, estudantes de Governador Valadares, cidade localizada a $320 \mathrm{~km}$ a leste da capital do estado mineiro, embora também receba estudantes de distritos rurais vinculados à sede do município. O perfil socioeconômico dos estudantes da escola Urbana é variado e, como ela conta com programas de auxílio socioeconômico estudantil, a seleção é feita via edital, de forma que os estudantes mais carentes financeiramente recebem o benefício. Adicionalmente, há também a possibilidade de bolsas para monitoria, projetos de iniciação científica, projetos de extensão e projetos de ensino.

No semestre 2020-2, a escola contava com estudantes nos cursos técnicos integrados ao ensino médio $\left(1^{\circ}, 2^{\circ}\right.$ e $3^{\circ}$ anos) em (i) Edificações, (ii) Meio Ambiente e (iii) Segurança do Trabalho; dois cursos técnicos subsequentes em (i) Segurança do Trabalho e (ii) Serviços Jurídicos; quatro cursos superiores, sendo (i) Bacharelado em Engenharia de Produção, (ii) Bacharelado em Engenharia Ambiental e Sanitária, (ii) Bacharelado em Engenharia Civil e (iv) Superior de Tecnologia em Gestão Ambiental, além do curso de Pós-graduação em Engenharia de Segurança do Trabalho. Assim, a escola Urbana possuía, no segundo semestre de 2020, estudantes com idade que variava de 15 a 45 anos.

A escola Rural, por sua vez, atende estudantes da comunidade de Tuiutiba, distrito pertencente ao Município de Campo Formoso, interior da Bahia, além de estudantes de povoados circunvizinhos. O município se localiza na região norte do estado baiano e dista 401 $\mathrm{km}$ da capital. Os estudantes da unidade Tuiutiba possuem perfil socioeconômico diversificado; porém, boa parte de suas famílias se encontra cadastrada no programa Bolsa Família do governo federal, o que aponta para o fato de ser uma comunidade predominantemente formada por famílias de baixa renda per capita.

Nas turmas ofertadas no turno vespertino, os estudantes possuíam média de idade entre 15 e 17 anos, enquanto as turmas do turno noturno contavam com estudantes com idades que variavam de 16 até 45 anos. A unidade contava com cinco salas de aula, cantina, secretaria e sala dos professores. De acordo com Censo Escolar 2019, o Colégio Estadual do Campo de 
Campo Formoso - BA, Anexo Tuiutiba, contava com aproximadamente 200 estudantes na etapa do Ensino Médio.

Os pesquisadores atuavam como professores nas instituições de ensino locus desta pesquisa, fator que facilitou o contato com os estudantes e com as equipes administrativa e pedagógica.

Os dados apontaram que a maioria dos participantes foi do sexo feminino (72\%), conforme Figura 1-a, e suas idades variaram entre 15 e 21 anos. A participação encontra-se bem distribuída entre as duas instituições de ensino, sendo 52\% dos participantes da escola Urbana e 48\% vinculados à escola Rural (Figura 1-b). É preciso ressaltar a participação dos estudantes da escola Rural que, impossibilitados de utilizar os computadores da escola, ainda assim conseguiram participar da pesquisa. Portanto, considera-se significativa a participação desses estudantes, visto que a maioria deles não tinham acesso à internet e o período ainda era de adaptação ao modelo de ensino remoto e acesso aos materiais no meio virtual.

Figura 1 - Perfil dos participantes da pesquisa

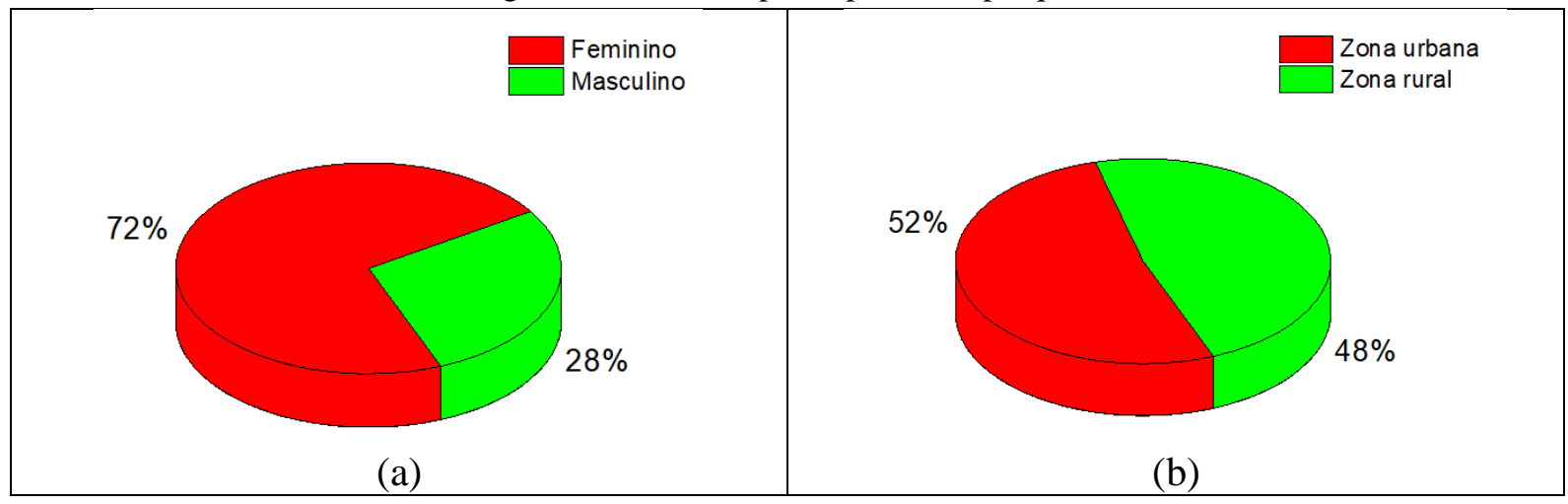

Fonte: Dados colhidos no formulário eletrônico (2021).

A primeira pergunta do formulário foi: “As questões ambientais ocupam cada vez mais espaço entre as discussões na sociedade e na mídia. O que você pensa sobre este assunto?”, sendo apresentado ao estudante as opções Ruim, Chato, Indiferente e Importante. Todos os estudantes consideraram importante que o debate sobre as questões ambientais estivessem presentes na mídia e na sociedade.

Buscando alicerce em Dias (2004), nota-se que o estudante reconhece que a EA é assunto corrente nas mídias às quais ele tem acesso. Segundo o autor, a EA deve ser trabalhada no ambiente escolar uma vez que se caracteriza por incorporar as dimensões sociais, políticas, econômicas, culturais, ecológicas e éticas, o que significa que, ao tratar de qualquer problema ambiental no ambiente escolar, os professores deveriam considerar todas essas dimensões. 
Gomes et al. (2016) e Cavalcante (2020) também apontam ser necessário que a escola ofereça os conhecimentos ecológicos básicos para que os estudantes compreendam que fazem parte de um sistema dinâmico e integrado com a natureza. Dessa forma, a instituição escolar deve compreender que os estudantes reconhecem a temática ambiental nos âmbitos em que vivem e que é preciso trazê-la à discussão para que estes indivíduos passem a compreender a importância de adquirir hábitos de comportamento ecologicamente corretos.

A partir do formulário, verificou-se que a EA é trabalhada em alguma disciplina curricular nas duas instituições pesquisadas. Ao responderem à questão "Seus professores abordam temas e questões ambientais em sala de aula?", 92\% dos estudantes informaram que os professores têm incluído a temática ambiental em suas práticas pedagógicas. De maneira a aprofundarmos a compreensão sobre como este trabalho com a EA tem sido organizado, foi solicitado aos estudantes que indicassem quais eram as disciplinas que incluíam a temática no cotidiano de estudos e quais eram os temas ambientais mais trabalhados nas atividades dessas disciplinas.

Especificamente para a escola Urbana, por se tratar de um curso técnico integrado ao ensino médio e à área específica de Meio Ambiente, os estudantes responderam que a EA se mostrava presente nas discussões da maioria das disciplinas, inclusive daquelas de caráter técnico (Figura 2-a), com destaque para Geografia, Área Técnica e Biologia.

Por sua vez, os estudantes da escola Rural também indicaram que a EA se fazia presente na maioria das disciplinas que compunham a matriz curricular do curso, com destaque para Geografia (Figura 2-b). Contudo, notou-se nessa instituição uma maior homogeneidade entre as disciplinas, sugerindo que a EA perpassa uma maior quantidade de disciplinas e em maior profundidade. Embora não tenha sido um dado da pesquisa, essa homogeneidade sugere uma maior aproximação com os preceitos trazidos pela PNEA, especialmente quanto ao trabalho interdisciplinar para o desenvolvimento da EA. 
Figura 2 - Disciplinas que abordam a temática EA na escola Urbana (a) e na escola Rural (b)

a)

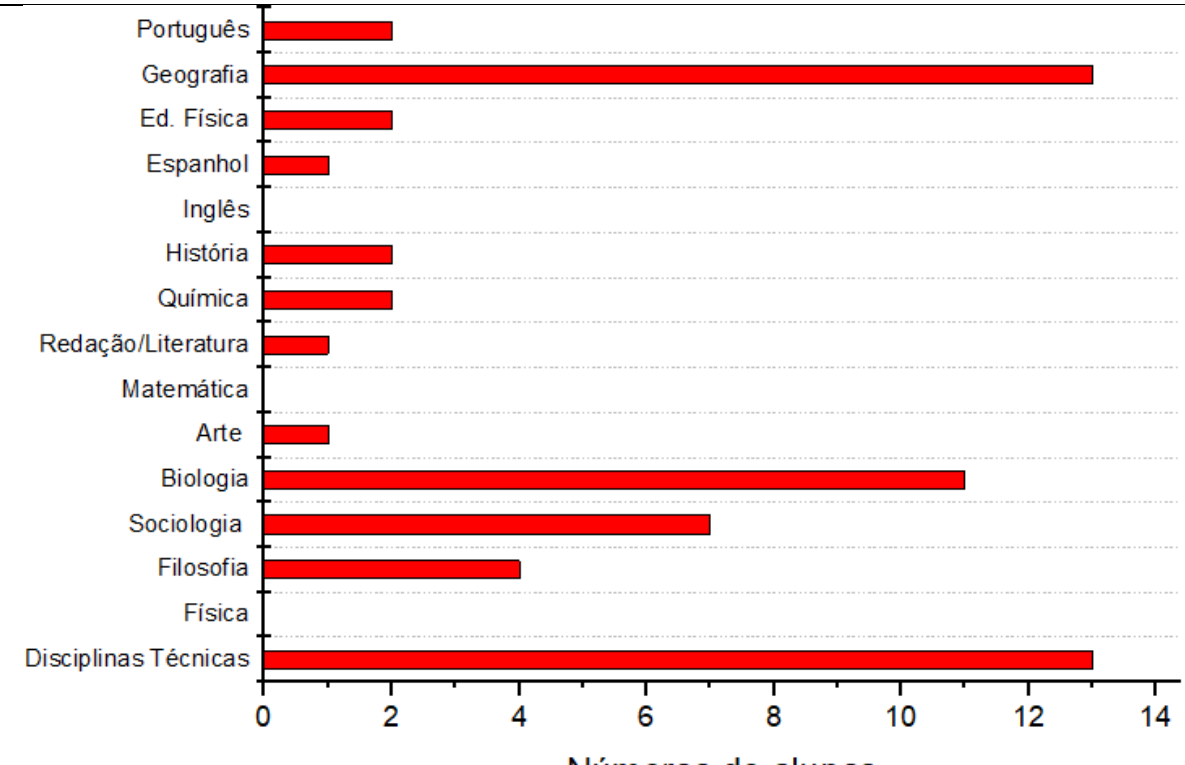

Números de alunos

b)

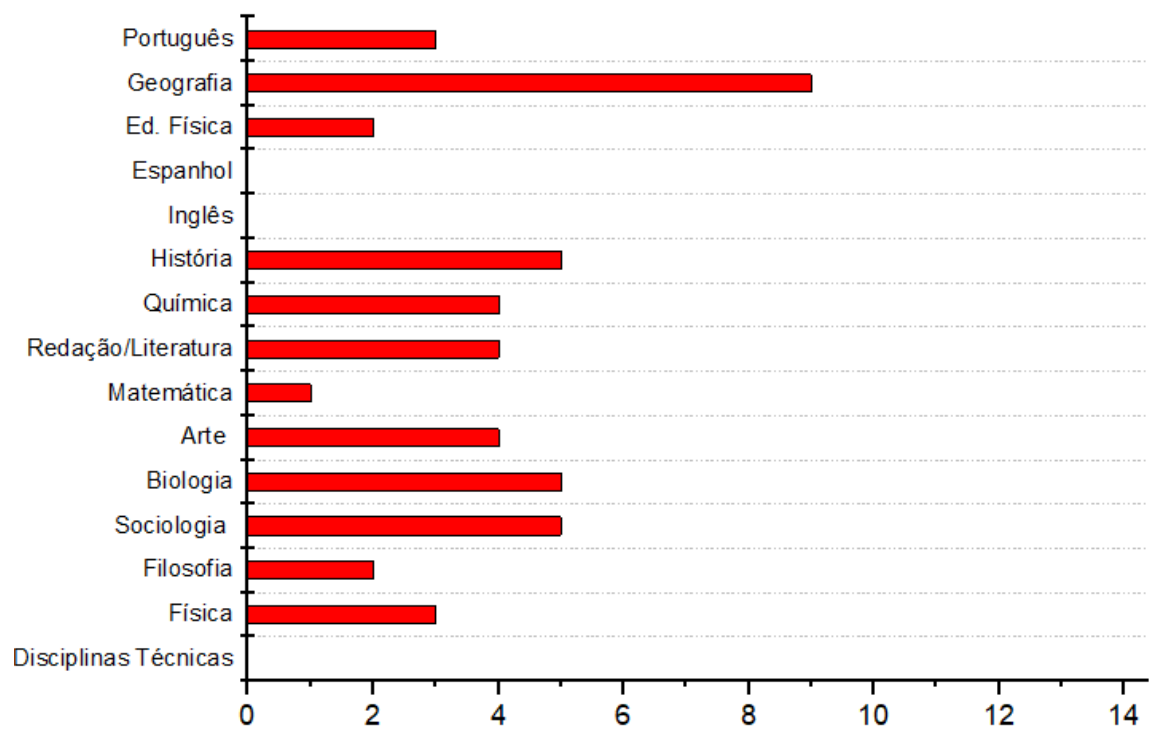

Números de alunos

Fonte: Dados colhidos no formulário eletrônico (2021).

Em ambas as instituições, o destaque que a Geografia conseguiu corrobora com uma evidência histórica no trabalho com a EA, contemplando as relações entre a sociedade e a natureza de forma integrada, objetivando levar os educandos à sensibilização por entenderem que eles são parte integrante do meio ambiente e pela constatação de que os humanos são, na maioria das vezes, os responsáveis pela modificação do espaço geográfico.

Também chamou a atenção, durante a análise dos dados, o fato dos estudantes de ambas as instituições de ensino indicarem que os professores da disciplina Inglês não incluíam a EA em suas práticas pedagógicas. Conforme orientações constantes nas legislações educacionais brasileiras, é necessário que todas as disciplinas criem estratégias para inserir em seus 
planejamentos assuntos que relacionem o conteúdo específico com a temática ambiental. A PNEA, especificamente, orienta para que a EA seja trabalhada de modo transversal, contínuo e permanente em todas as disciplinas (BRASIL, 1999), reforçando a orientação que já estava expressa nas diretrizes curriculares nacionais (BRASIL, 1998). Complementarmente, a Base Nacional Comum Curricular (BNCC) não estabelece que a EA deva ser trabalhada como componente curricular específico, propondo que se incorporem aos currículos e às propostas pedagógicas a abordagem de temas contemporâneos, preferencialmente de forma transversal e integradora (BRASIL, 2018).

Também é possível observar que em ambas as instituições, os professores das disciplinas Matemática, Língua Portuguesa e Física têm encontrado dificuldades em inserir temas relacionados à EA nas práticas pedagógicas, constatação possivelmente relacionada a uma carência de conhecimentos específicos sobre o tema. Jacobi (2007) chama a atenção para a potencialidade de se trabalhar a EA nas disciplinas curriculares, com possibilidade de o professor desenvolver propostas pedagógicas focadas na sensibilização, mudança de comportamento, formação, capacidade de avaliação e participação dos estudantes.

O cotidiano das instituições de ensino brasileiras enfrenta muitos desafios à efetivação de um trabalho interdisciplinar com a EA, contudo. É possível que o mais crítico seja o fato de os currículos estarem cada vez mais herméticos, vinculados fielmente às avaliações de larga escala, resultando, consequentemente, em pouco espaço de manobra para relacionar os conteúdos específicos da disciplina a uma discussão crítica da EA. Soma-se a isso instituições escolares com deficiências estruturais e déficit de recursos, pouco ou nenhum investimento em ações de formação continuada dos educadores (VALDERRAMA-HERNÁNDEZ; ALCÁNTARA; LIMÓN, 2017; SILVA; MEDEIROS; CARAMELLO, 2020; KOLCENTI; MÉDICI; LEÃO, 2020).

Trajber e Mendonça (2007), por sua vez, afirmam que os trabalhos no ambiente escolar que envolvem a temática ambiental têm focado nas disciplinas de Ciências Naturais e Geografia, o que evidencia a dependência da EA com as disciplinas chamadas afins, fato constatado em grande medida nas instituições analisadas. Além disso, é necessário ressaltar que essas disciplinas, isoladamente, são insuficientes para se desenvolver toda a potencialidade da EA, reforçando a necessidade de as escolas privilegiarem projetos e ações que envolvam todas as disciplinas do curso (SILVA; SILVA, 2020; KOLCENTI; MÉDICI; LEÃO, 2020). Nesse mesmo entendimento, Santos e Santos (2016) indicam que delegar uma temática tão ampla 
quanto a EA exclusivamente aos professores dessas disciplinas reduz a sua importância, vincula-a a exposições apenas em datas comemorativas, tirando-lhe a oportunidade de uma discussão mais apurada e crítica.

As respostas obtidas em relação à EA na escola Urbana registram que os principais temas abordados em sala de aula foram: desmatamento, aquecimento global, queimadas, resíduos sólidos e água (conforme Figura 3-a). Na escola Rural, os estudantes apontaram como principais temas abordados: aquecimento global, o desmatamento, a água, as queimadas e a flora (conforme Figura 3-b).

Figura 3 - Principais assuntos ligados à EA abordados na escola Urbana (a) e na escola Rural (b)

a)

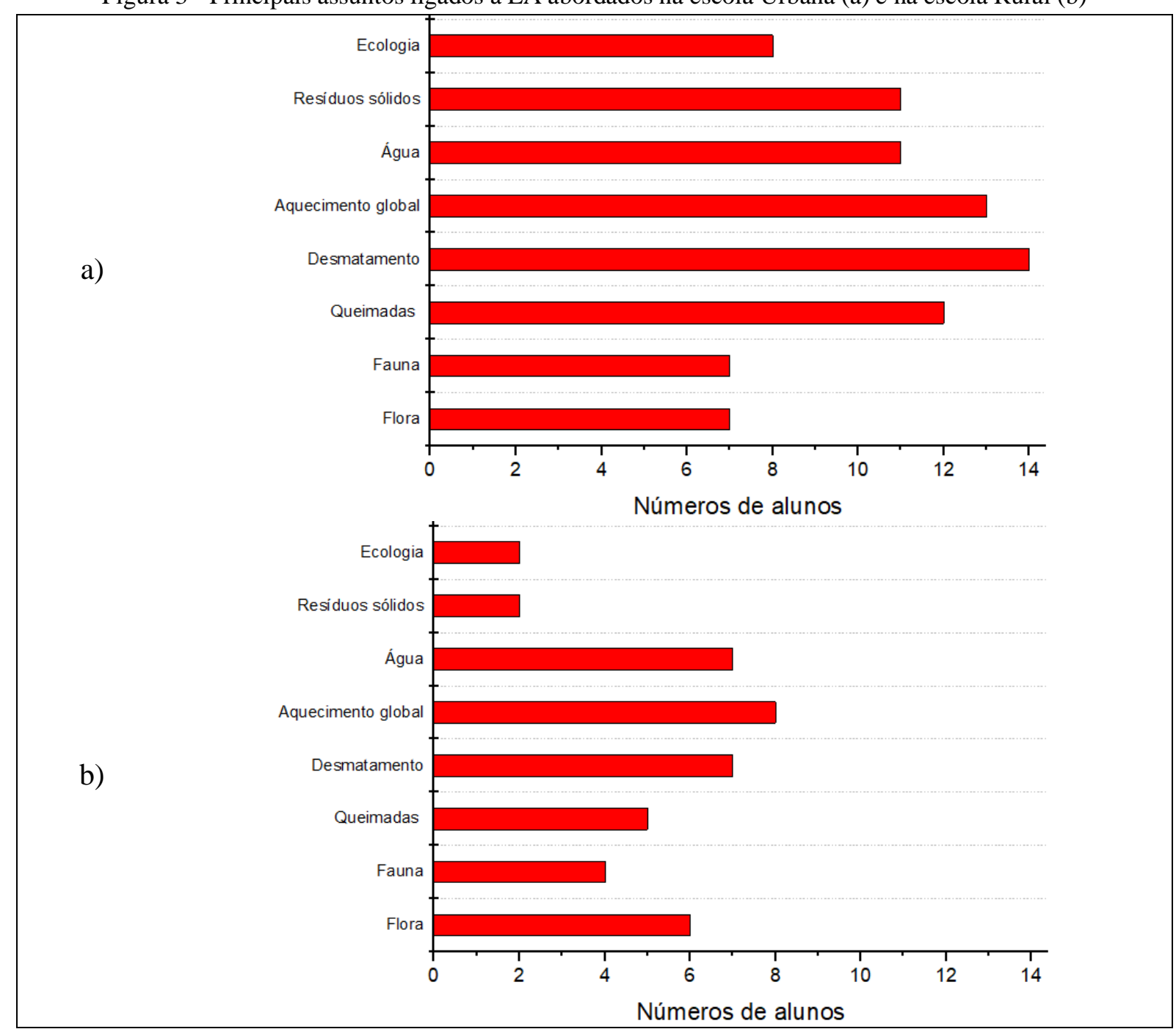

Fonte: Dados colhidos no formulário eletrônico (2021)

Chama a atenção o fato de praticamente todos os estudantes da escola Urbana (Figura 3-a) reconhecerem diversos temas nas práticas pedagógicas no curso Técnico em Meio Ambiente. Conforme Figura 2-a, essa instituição de ensino apresentou, segundo os estudantes, 
uma maior concentração das discussões com a EA nas disciplinas técnicas, Geografia e Biologia. Comparando os dados das duas figuras (2-a e 3-a), pode-se inferir que, apesar da concentração em três disciplinas, o trabalho com a temática EA tem se mostrado bastante abrangente e trazendo diversos assuntos - fator que potencializa uma visão holística sobre o Meio Ambiente e os impactos da ação antrópica. Por outro lado, observa-se que os estudantes da escola Rural têm identificado em menor frequência a presença de fatores que tratam da questão ambiental nas práticas pedagógicas do cotidiano escolar.

Inegavelmente, os dados retratam a realidade didático-pedagógica de dois cursos distintos, sendo o primeiro deles específico na área (Técnico em Meio Ambiente) e o outro generalista, o que justifica a maior presença das discussões no primeiro. Contudo, ainda que específico e com maior presença das discussões no cotidiano escolar, o primeiro curso não tem tratado a EA de maneira mais ampla e com maior abrangência curricular, conforme a PNEA apregoa. Buscando referência em Junges, Santos e Massoni (2018), de fato esses temas elencados na Figura 3 têm exercido uma grande influência nas discussões globais. Diversos países têm estabelecido estratégias para reduzir a emissão de gases causadores do efeito estufa, propondo a criação de projetos ambientalmente responsáveis, por exemplo. Ainda conforme os autores, cabe ressaltar que esses problemas estão atrelados ao consumismo exacerbado, ao processo de industrialização, entre outros fatores, e uma EA crítica contribui fortemente para a superação desse quadro global.

A próxima pergunta fez referência à importância dada pelos estudantes ao tema EA na escola. Em ambas as instituições, todos os estudantes consideraram importante que a temática ambiental fosse discutida em sala de aula desde os primeiros anos escolares. Assim, reconhece-se a valorização dada pelos estudantes no estudo e debate das questões relacionadas ao meio ambiente no ambiente formal de ensino-aprendizagem em conjunto com seus colegas e professores. Os estudantes da escola Rural, por exemplo, relataram questões relacionadas à fauna, à flora e à poluição do ar, enquanto aqueles da escola Urbana reconheceram a poluição de rios, do ar e os problemas de saúde ligados à contaminação ambiental como mais preocupantes. Observa-se que os indivíduos conseguem reconhecer a presença do Meio Ambiente em seus cotidianos e os fatores que comprometem a sua qualidade, quer estejam em um ambiente rural ou urbano.

As discussões acerca do espaço da EA no currículo escolar são muito importantes, visto que a escola é o ambiente propício para a formação do cidadão. Virgens (2011) afirma que a 
escola deve interagir com as transformações ocorridas no ambiente que a rodeia, para que a EA possa se instituir como prática educativa. Para Jacobi (2007), a escola deve ainda garantir uma EA que propicie novas atitudes e comportamentos face ao consumo em nossa sociedade, além de estimular a mudança de valores individuais e coletivos.

Também foi perguntado aos estudantes: "Você conhece alguma ação que tenha sido ou é realizada pela sua escola que envolva a preservação e melhoria do meio ambiente?". Observou-se que ambas as instituições têm desenvolvido essas ações, visto que 80\% responderam afirmativamente. O Quadro 1 organiza as ações desenvolvidas na escola Rural e na escola Urbana, segundo os respondentes.

Quadro 1 - Ações desenvolvidas nas escolas cujo foco esteve relacionado à preservação e/ou à melhoria do meio ambiente

\begin{tabular}{|c|c|}
\hline Escola Urbana & Escola Rural \\
\hline $\begin{array}{ll}\checkmark & \text { Feiras de ciências } \\
\checkmark & \text { Ponto de coleta de material reciclável } \\
\checkmark & \text { Realização de palestras e minicursos } \\
\checkmark & \text { Projeto de extensão } \\
\checkmark & \text { Plantação de árvores em volta da escola e } \\
& \text { área desmatada } \\
\checkmark & \text { Horta do campus }\end{array}$ & $\begin{array}{ll}\checkmark & \text { Feiras de ciências } \\
\checkmark & \text { Ponto de coleta de material reciclável } \\
\checkmark & \text { Distribuição de plantas para a comunidade } \\
\checkmark & \text { Plantação de árvores em volta da escola }\end{array}$ \\
\hline
\end{tabular}

Fonte: Dados colhidos no formulário eletrônico (2021).

Os dados apontam uma padronização de atividades presentes nos ambientes escolares ao se trabalhar a temática ambiental. Destaca-se que na escola Urbana, os estudantes indicaram a realização de palestras e minicursos sobre diversos temas ambientais como, por exemplo, compostagem, o crime ambiental e social provocado pelo rompimento das barragens de rejeitos minerais em Brumadinho e Mariana e a Horta do campus. Também foi destacado pelos estudantes o projeto de extensão "Proposta de implantação e manutenção de unidades demonstrativas de hortas verticais/horizontais, viveiro e estufa de baixo custo como ferramenta de EA para a comunidade acadêmica do IFMG-GV e externa"1.

$\mathrm{Na}$ escola Rural, nenhum estudante mencionou a realização de eventos, palestras ou cursos voltados para a EA. Possivelmente, essa constatação tem relação com as deficiências estruturais e déficit de recursos, além da falta de investimento em ações de formação continuada dos educadores (VALDERRAMA-HERNÁNDEZ; ALCÁNTARA; LIMÓN, 2017; SILVA; MEDEIROS; CARAMELLO, 2020; KOLCENTI; MÉDICI; LEÃO, 2020).

\footnotetext{
1 Do projeto de extensão derivaram outros estudos e projetos. Para maior esclarecimento, visite https://www.ifmg.edu.br/portal/noticias/horta-do-campus-governador-valadares-lugar-de-ensino-pesquisa-eextensao.
} 
Todos os estudantes da escola Urbana responderam afirmativamente quando questionados se tinham conhecimento de problemas ambientais em seus respectivos municípios. Já para os estudantes da escola Rural, uma parcela de $72 \%$ afirmou existir problemas ambientais no município; $22 \%$ destes não conseguem identificar problemas ambientais no entorno.

Questionados sobre quem seriam os responsáveis pelos problemas ambientais em suas cidades, os estudantes das duas instituições apontaram ser a própria comunidade e as autoridades governamentais. Importa destacar que esses dados trazem à tona a discussão sobre os problemas ambientais nas comunidades e a falta das práticas de EA nestas.

Ao serem questionados quais seriam os problemas ambientais identificados por eles, os estudantes da escola Rural (Campo Formoso-BA) mencionaram: (i) queimadas no período de seca; (ii) desmatamento; e ( $i i i)$ a poluição gerada pela fábrica de cimento existente na cidade. Em contrapartida, os estudantes da escola Urbana (Governador Valadares-MG) citaram: (i) a ausência de uma estação de tratamento de esgoto; (ii) o descarte de esgoto in natura no Rio Doce; e (iii) o desmatamento frequente de áreas nativas para construção de prédios.

Observa-se que os estudantes conseguiram relacionar os problemas ambientais à dicotomia economia e meio ambiente. No Quadro 2, observam-se quantas vezes cada problema foi mencionado pelos estudantes das escolas Urbana e Rural.

Quadro 2 - Problemas ambientais identificados pelos estudantes em seus respectivos municípios

\begin{tabular}{|c|c|c|}
\hline Estudante & Escola Urbana & Escola do Campo \\
\hline A3 e A7 & & Fábrica de cimento e poluição \\
\hline $\mathrm{A} 3, \mathrm{~A} 4, \mathrm{~A} 5, \mathrm{~A} 6, \mathrm{~A} 7, \mathrm{~A} 8, \mathrm{~A} 9$ & & Desmatamento, queimadas \\
\hline $\mathrm{A} 14, \mathrm{~A} 16, \mathrm{~A} 20, \mathrm{~A} 26, \mathrm{~A} 27, \mathrm{~A} 28$ & $\begin{array}{l}\text { Queimadas, desmatamento e } \\
\text { poluição do Rio Doce }\end{array}$ & \\
\hline $\begin{array}{c}\mathrm{A} 15, \mathrm{~A} 17, \mathrm{~A} 18, \mathrm{~A} 19, \mathrm{~A} 20, \mathrm{~A} 21, \\
\mathrm{~A} 22, \mathrm{~A} 23, \mathrm{~A} 24, \mathrm{~A} 25, \mathrm{~A} 26\end{array}$ & $\begin{array}{c}\text { Tratamento de esgoto/ } \\
\text { Saneamento básico e falta de } \\
\text { aterro sanitário }\end{array}$ & \\
\hline A 25 & $\begin{array}{l}\text { O ponto de coleta de material } \\
\text { reciclável }\end{array}$ & \\
\hline
\end{tabular}

* Constam apenas as principais categorias citadas pelos estudantes.

Fonte: Dados colhidos no formulário eletrônico (2021).

Com o intuito de investigar se os estudantes teriam noção da relação dos poderes públicos com a preservação do Meio Ambiente, o formulário eletrônico apresentou aos estudantes a pergunta "Você entende que, no município onde você mora, o poder público tem desenvolvido ações que promovem a preservação do Meio Ambiente?". A maior parte dos estudantes respondeu afirmativamente, conforme exposto na Figura 4. 
Figura 4 - Reconhecimento de ações do Poder Público para a preservação do Meio Ambiente, de acordo com os estudantes da escola Urbana (a) e escola Rural (b)

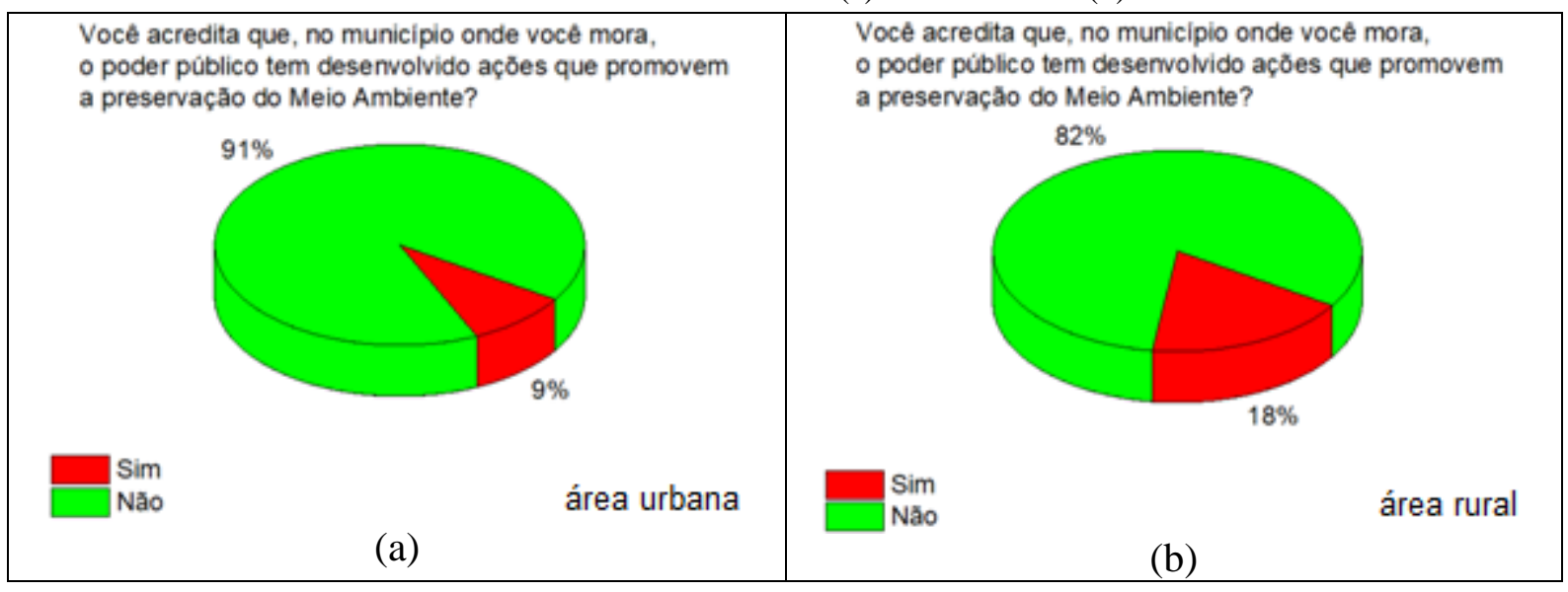

Fonte: Dados colhidos no formulário eletrônico (2021).

Aos estudantes que responderam afirmativamente, foi adicionada a pergunta "Você conhece alguma ação específica do Poder Público realizada no município onde você mora para proteger o meio ambiente?" e apenas uma estudante da escola Urbana citou a plantação de árvores nas ruas. Nota-se, portanto, que os estudantes de ambas as instituições reconhecem no Poder Público a responsabilidade em desenvolver ações de preservação ambiental, mas não têm conhecimento destas. Aqui não se trata de defender especificamente um incentivo à propaganda dos atos dos poderes executivo, legislativo e judiciário com a questão ambiental, embora essa medida também seja importante para dar visibilidade à causa. Trata-se de discutir a responsabilidade de cada um dos poderes públicos na construção de um ambiente saudável para a geração atual e as próximas, conforme o texto constitucional.

Por fim, os estudantes foram questionados "Você já fez ou faz alguma ação para melhorar elou conservar o Meio Ambiente?". A maioria dos estudantes das duas instituições de ensino respondeu afirmativamente, o que demonstrou uma preocupação dos jovens com a preservação do Meio Ambiente, independentemente de morarem em um ambiente urbano ou rural. Nas respostas dos estudantes da escola Rural, encontram-se ações de proteção dos animais, plantação de árvores e reciclagem, atitudes que remetem à preocupação daqueles estudantes com a preservação da fauna, da flora e dos recursos naturais. Também relataram o plantio do próprio alimento, fator que guarda relação com a região onde moravam e na qual as famílias ainda cultivavam o seu alimento em pequenas lavouras.

Nas respostas dos estudantes da escola Urbana, por sua vez, constam elencadas ações de descarte adequado do lixo, de economia de água e de energia, a plantação de árvores e a recuperação de nascentes. Destaca-se que na cidade de Governador Valadares-MG, o Rio 
Doce é um importante recurso natural para os seus habitantes e o crime ambiental e social provocado pela queda da barragem da mineradora Samarco em $2015^{2}$ afetou os estudantes e seus familiares, direta e/ou indiretamente, inclusive gerando problemas de saúde resultantes da contaminação das águas do rio. Nas respostas destes estudantes, nota-se uma relação entre a produção de produtos industrializados e o descarte do lixo gerado nestes processos, além da relação muito próxima com o Rio Doce e suas nascentes.

\section{CONSIDERAÇões FinAIS}

Ao propormos um estudo que analisaria as percepções de estudantes matriculados em cursos e instituições geográfica e culturalmente distantes, tínhamos a existência de diferenças por hipótese, baseados em Dias (2010). Fatores de ordem econômica e de infraestrutura já criaram essa diferenciação: uma instituição é federal e outra estadual, embora ambas fossem públicas, as condições da escola de Campo Formoso-BA, especialmente no Anexo Tuiutiba, eram limitadas. A falta de laboratórios poderia ser um fator que prejudicaria a proposição de projetos de pesquisa e de extensão, por exemplo.

Ao analisar os dados coletados pelo formulário eletrônico, este estudo evidenciou que, embora participassem estudantes de uma escola urbana e outra rural, as recomendações da PNEA ainda não se materializaram nas práticas pedagógicas no cotidiano dos cursos. Enquanto os estudantes da escola Urbana demonstraram estar mais cientes dos problemas que afetam o Meio Ambiente, estas discussões ainda estão concentradas principalmente em Geografia, Biologia e nas disciplinas técnicas, perseverando o desafio de incluir discussões temáticas nas disciplinas da área de Exatas, assunto abordado por Jacobi (2007). Na escola Rural, por sua vez, há uma homogeneidade em práticas pedagógicas que tratam da EA, embora os estudantes tenham tido dificuldades de listarem problemas ambientais em estudos já realizados nas disciplinas dos seus cursos. Ou seja, há o trabalho com a EA, mas este tem sido pouco frequente e/ou apenas restrito a um evento ou data comemorativa.

O estudo também apontou que os estudantes precisam conhecer as atribuições dos poderes executivo, legislativo e judiciário; também é importante que eles reconheçam as obrigações destes entes nas esferas municipal, estadual e federal. Os dados recolhidos na pesquisa indicam que os jovens têm conhecimento de que o Poder Público tem obrigações para

\footnotetext{
${ }^{2}$ Disponível em: http://g1.globo.com/mg/minas-gerais/noticia/2019/01/25/ha-3-anos-rompimento-de-barragemde-mariana-causou-maior-desastre-ambiental-do-pais-e-matou-19-pessoas.ghtml. Acesso em: 04 nov. 2020.
} 
a preservação do Meio Ambiente, mas não conseguiram listar quais ações tinham sido realizadas.

Por fim, nota-se a urgência para que os profissionais de educação tenham acesso a ações de formação continuada de modo a serem encorajados a inserir a temática ambiental em suas atividades educacionais (e cotidianas). Dessa forma, partindo da escola ou intensificando a discussão a partir dela, potencializaremos os debates que alcançam os modos de vida, os processos de produção industrial e a relação das comunidades com o Meio Ambiente, conforme também discutido por Trajber e Mendonça (2007), Santos (2009) e Raymundo et al. (2019).

O estudo evidenciou que o meio cultural e geográfico do estudante influencia no conhecimento, na relação do indivíduo com o Meio Ambiente e na importância que eles atribuem aos problemas ambientais. É importante discutirmos os problemas que assolam o planeta, mas, ainda mais urgente é identificarmos aqueles problemas que estão em nosso entorno imediato, ou seja, é essencial que os estudantes reconheçam os problemas ambientais que os rodeiam, não importa se analisamos um espaço urbano ou rural.

Este estudo contribui para a discussão de práticas pedagógicas relacionadas à EA e as potencialidades destas na construção de ações de preservação do Meio Ambiente. Questionar os maus hábitos em relação ao consumo exagerado dos recursos naturais, como também de produtos industrializados, procurando minimizar a produção de resíduos, são ações que irão beneficiar a nossa geração e as gerações futuras.

\section{REFERÊNCIAS}

BRASIL. Constituição da República Federativa do Brasil de 1988. Disponível em: http://www2.senado.leg.br/bdsf/bitstream/handle/id/518231/CF88_Livro_EC91_2016.pdf. Acesso em 5 abr. 2021.

BRASIL. Lei no 9.795, de 27 de abril de 1999. Dispõe sobre a Educação Ambiental, institui a Política Nacional de Educação Ambiental e dá outras providências. Disponível em: http://portal.mec.gov.br/secad/arquivos/pdf/educacaoambiental/lei9795.pdf. Acesso em: 21 set. 2020.

BRASIL. Ministério da Educação. Parâmetros Curriculares Nacionais (PCN): Temas Transversais. Brasília (BRASIL): MEC, 1998. 436 p.

BRASIL. Lei $\mathbf{n}^{\mathbf{0}}$ 13.005, de 25 de junho de 2014. Aprova o Plano Nacional de Educação (PNE) e dá outras providências. Brasília: Câmara dos Deputados, Edições Câmara, 2014.

BRASIL. Ministério da Educação. Portaria no 1.144, de 10 de outubro de 2016. Institui o Programa Novo Mais Educação, que visa melhorar a aprendizagem em Língua Portuguesa e Matemática no ensino. Brasília: Diário Oficial da União, 2016. 
BRASIL, Ministério da Educação. Etapa do Ensino Médio é homologada e Base Nacional Comum Curricular está completa. Brasília: MEC. 2018. Disponível em:

http://portal.mec.gov.br/component/content/article?id=72011. Acesso em 5 abr. 2021.

CAVALCANTE, Josinaldo. Educação Escolar e Meio Ambiente: uma análise a partir de Estudantes e Professores do Ensino Médio. Open Minds International Journal, v. 1, n. 1, p. 64-75, 1 jul. 2020. http://doi.org/10.47180/omij.v1i1.17.

DIAS, Genebaldo Freire. Educação Ambiental: princípios e práticas. São Paulo: Gaia, 2004.

FRIZZO, Taís Cristine Ernst; CARVALHO, Isabel Cristina de Moura. políticas públicas atuais no Brasil: o silêncio da Educação Ambiental. REMEA - Revista Eletrônica do Mestrado em Educação Ambiental, [S. l.], n. 1, p. 115-127, 2018. DOI:

10.14295/remea.v0i1.8567. Disponível em: http://periodicos.furg.br/remea/article/view/8567. Acesso em: 5 abr. 2021.

GASQUES, Ana Carla Fernandes; OKAWA, Cristhiane Michiko Passos; SANTOS, Jordana Dorca dos; GASQUES, Elisabet Gabrieli Fernandes; DELABIO, Francielle. Educação Ambiental: Estudo de caso em dois Colégios Estaduais da cidade de Sarandi (PR). Revista Brasileira de Educação Ambiental (RevBEA), v. 11, n. 5, 123-138, 2016. Disponível em: http://revbea.emnuvens.com.br/revbea/article/view/4984. Acesso em 5 abr. 2021.

GIL, Antônio Carlos. Métodos e Técnicas de Pesquisa Social. 6 ed. São Paulo: Editora Atlas, 2002.

GOMES, Carlos Mário Ribeiro; NASCIMENTO, Andrea Amaro; SOUZA, Amay Fernandes Silva; SANTANA, Willma José de. Análise das práticas de Educação Ambiental em duas escolas de ensino médio na cidade de juazeiro do norte-CE. Revista Gestão \&

Sustentabilidade Ambiental, Florianópolis, v. 5, n. 1, p. 26-41, abr./set. 2016. Disponível em: http://www.portaldeperiodicos.unisul.br/index.php/gestao_ambiental/article/view/2706. Acesso em 5 abr. 2021.

JACOBI, Pedro Roberto. Educar na sociedade de risco: o desafio de construir alternativas. Pesquisa em Educação Ambiental, São Carlos, v. 2, n. 2, p. 49-65, 2007. DOI: http://doi.org/10.18675/2177-580X.vol2.n2.p49-65.

JUNGES, Alexandre Luis; SANTOS, Vinícius Yuri; MASSONI, Neusa Teresinha. Efeito estufa e aquecimento global: uma abordagem conceitual a partir da física para educação básica. Experiências em Ensino de Ciências. v.13, n.5, 2018. Disponível em: http://if.ufmt.br/eenci/artigos/Artigo ID531/v13 n5 a2018.pdf. Acesso em 7 abr. 2021.

KOLCENTI, Sandra Gonçalves Ribeiro; MÉDICI, Mônica Strege; LEÃO, Marcelo Franco. Educação Ambiental em escolas públicas de Mato Grosso. Revista Científica ANAP Brasil. Volume 13, número 29, 2020. Disponível em:

http://www.amigosdanatureza.org.br/publicacoes/index.php/anap_brasil/article/view/2594. Acesso em 5 abr. 2021.

ORGANIZAÇÃO DAS NAÇOES UNIDAS (ONU). Declaração de Estocolmo sobre o Meio Ambiente Humano. Estocolmo: ONU, 1972. 
RAYMUNDO, Maria Henriqueta Andrade; BIASOLI, Semíramis; BRANCO, Evandro Albiach; SORRENTINO, Marcos. Avaliação e monitoramento de políticas públicas de Educação Ambiental no Brasil: transição para sociedades sustentáveis. Piracicaba: MH Ambiente Natural, 2019.

SANTOS, Luana Magda Muniz dos. A importância de práticas de ensino criativas na Educação Ambiental. In: VII ENCONTRO NACIONAL DE PESQUISA EM EDUCAÇÃO EM CIÊNCIAS. Anais, Florianópolis, 8 nov. 2009.

SANTOS, Aline Gomes dos; SANTOS, Crisliane Aparecida Pereira. A inserção da Educação Ambiental no currículo escolar. Revista Monografias Ambientais - REMOA, v. 15, n.1, jan-abr. 2016. Disponível em: http://periodicos.ufsm.br/remoa/article/view/19893. Acesso em 5 abr. 2021.

SILVA, Decauita Poliana Peixoto da; MEDEIROS, Patrícia Soares de Maria de;

CARAMELLO, Núbia Déborah Araújo. Percepção de educadores sobre aspectos da Educação Ambiental em escolas do município de Ji-Paraná/RO. Revista Ibero Americana de Ciências Ambientais, v.11, n.6, p.688-699, 2020. Disponível em:

http://www.sustenere.co/index.php/rica/article/view/CBPC2179-6858.2020.006.0055. Acesso em 5 abr. 2021.

SILVA, Fredson Pereira da; SILVA, Camila Castro e. Uma abordagem sobre a importância da interdisciplinaridade no ensino da Educação Ambiental na escola. Revista Brasileira de Meio Ambiente, v.8, n.4, 2020. Disponível em:

http://revistabrasileirademeioambiente.com/index.php/RVBMA/article/view/534. Acesso em 5 abr. 2021.

TRAJBER, Raquel; MENDONÇA, Patrícia Ramos. (Org.). Educação na diversidade: o que fazem as escolas que dizem que fazem Educação Ambiental. Brasília: Secretaria de Educação Continuada, Alfabetização e Diversidade, 2007.

VALDERRAMA-HERNÁNDEZ, Rocío; ALCÁNTARA, Lucía; LIMÓN, Dolóres. The complexity of environmental education: teaching ideas and strategies from teachers. Procedia - Social and Behavioral Sciences, v.237, p.968-974, 2017. Disponível em: http://idus.us.es/handle/11441/88181. Acesso em 5 abr. 2021.

VEIGA, Alinne; AMORIM, Érica; BLANCO, Maurício. Um retrato da presença da Educação Ambiental no ensino fundamental brasileiro: o percurso de um processo acelerado de expansão. Ministério da Educação. Instituto Nacional de Estudos e Pesquisas Educacionais Anísio Teixeira. Brasília, 2005. Disponível em:

http://portal.inep.gov.br/documents/186968/485287/Um+retrato+da+presen\%C3\%A7a+da+e

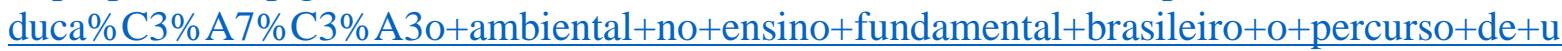
$\mathrm{m}+$ processo+acelerado+de+expans\%C3\%A3o/15869581-68fa-4c2f-a254-

6b94fad669b1?version=1.3. Acesso em 7 abr. 2021.

VIEIRA, Valter Afonso. As tipologias, variações e características da pesquisa de marketing. Curitiba, Revista da FAE, v.5, p.65-70, jan./abr. 2002.

VIRGENS, Rute de Almeida. A Educação Ambiental no ambiente escolar [Monografia]. Brasília: Universidade de Brasília e Universidade Estadual de Goiás; 2011. 26 p. 